\title{
CORRESPONDENCE
}

\section{TALE OF A WATERSHED: VISION FOR TOMORROW'S INDIA}

The above article by Sri Subhajyoti Das (JGSI, v.85(3), pp.386389) has brought to light succinctly, with examples from four areas in India, the efficacy of using modern technology, without ignoring traditional methods where relevant, in the rejuvenation of surface and/or ground water resources. It is good that it is slowly being realized, that instead of embarking on mega projects involving a lot of time, money and considerable wastage as well, the governments have come to realize the potentialities of watershed development. However, it is to the credit of some NGOs in a few parts of India, who undertook small projects in purely rain-fed and unirrigated lands, and augmented the water resources in small areas, that has attracted the attention of some planners at different levels in the country.

In a majority of such cases the labour involved is invariably voluntary, contributed by the local population and well-meaning social activists. Such studies leading to successful completion of those projects, where it is possible to trace the successive efforts made to bring to fruition the optimum utilization of the land, if made available for a wider audience, then the progress in this field will be very rewarding.

Apart from the 4 areas mentioned above, where such studies were made and results published, there was one on Kumadavathi river rejuvenation project in Karnataka (JGSI, 82(6), p.720, 2013). This was followed by one on Vedavati river, also in Karnataka, sponsored by the "Art of Living." What is noteworthy is that a video of about 8 minutes duration was prepared about this project with comments and explanations in Kannada and English with actual field photographs (Dr. Y. Lingaraju; rajuyale@yahoo.com). This was shown to interested farmers in similar areas and administrators in the State. There are among the politicians and bureaucrats, persons, even if they do not have time or inclination to visit areas of such projects, will at least be prepared to view and listen to presentations on such projects of vital importance to the country's progress and consider for appropriate funding. It should be admitted that it is not always possible to find financial resources by NGOs or the village folk alone to carry out such projects even if technically known to be feasible, without sufficient finance from elsewhere. Hence it is recommended that videos of all such projects with commentaries in the appropriate local languages be made and shown to the farmers and agencies, from the Panchayat level to the highest, so that more of such projects are initiated in different parts of the country. Perhaps these ventures will lead to sustainable development on different fronts on land utilization for a variety of purposes (as already listed in the article) and save substantial money being spent on mega projects on dams, reservoirs, linking of rivers etc.

E: rvaidya31@gmail.com R. VAIDYANADHAN
This article (JGSI, v.85(3), pp.386-389) is based on detailed expert analysis of various water Conservation Projects by the one who has vast experience of working in the groundwater sector in various capacities, especially with extensive field experience. It is a very informative and knowledge gaining article, like knowing developments in this sector from an expert, who took all the pain to review all such developments. The article has analysed and come out with types of such projects and linked it with the UN's MDG's, Clean India Campaign and suggested for the need to include the issue of spirituality for motivating dedication and commitment of the community for water security to improve productivity. Further it has also set strategic goals as vision for Tomorrow's India. It is almost like a review scientific paper.

On the whole it is welcome to have more such articles in the News and Notes Section which will be interesting for all readers.

E: kjanand@hotmail.com K.J. ANANDHA Kumar

\section{PETROLOGY IN GROUNDWATER STUDY}

This article (JGSI, v.85(2), pp.258-260) is very educative, research and application oriented and especially thought provoking. The article starts with three basic parameters which govern groundwater occurrence, flow and storage and explains the research in this field for understanding more on these parameters. It explains, which are the areas, where more research is needed to gain knowledge, so that it can assist in practical sustainable development of groundwater to meet the ever increasing demand. The last paragraph highlights the issues to be addressed by students and researchers to achieve this goal for the future.

It was an enjoyable reading and after reading it, one realises, that the issues highlighted are very much needed to be addressed, but never highlighted. Thanks for such a wonderful article which was so interesting.

E: kjanand@hotmail.com

K.J. ANANDHA Kumar 